\title{
Supply Chain Structure, Inventory Turnover, and Financial Performance: Evidence from Manufacturing Companies in China
}

\author{
Shanshan $\mathrm{Hu}^{*}$, Qing Ye ${ }^{\ddagger}$, Wei Chi ${ }^{\ddagger}$, Barbara B. Flynn* \\ * Kelley School of Business, Indiana University, Bloomington, Indiana, 47405, USA \\ $\ddagger$ School of Economics and Management, Tsinghua University, Beijing, 100084, China
}

Version: August 2010

\begin{abstract}
Using data collected by the World Bank, we empirically investigate the relationship between Chinese manufacturers' supply chain attributes, raw material and finished goods inventory turnover, and return on sales. Our findings indicate that location proximity, relationship continuity, and the relative power of the manufacturer over suppliers and customers have a significant impact on inventory performance, which in turn drives profitability. We especially focus on characteristics unique to China's business environment. We find that Chinese manufacturing companies have relatively weak operational performance, and better operational performance is associated with closer distance, longer relationship with suppliers and customers, and relative power over suppliers. Unlike their counter parties in some developed countries, Chinese manufacturers' profitability relies on both downstream and upstream inventory performance, with downstream inventory performance playing a somewhat more important role.
\end{abstract}

Key Words: Supply Chain Management, Inventory Turnover, Financial Performance, China Research.

\section{Introduction}

Its fast growing manufacturing capability has recently earned China the nickname of "the factory of the world". Despite the vast size of the Chinese manufacturing sector, its efficiency has not been widely applauded. Critical to a manufacturer's operational efficiency is inventory performance, as inventory accounts for a large percentage of a manufacturer's total 
assets. Supply chain management (SCM) can be an effective tool for reducing inventories, increasing inventory turnover, and reducing costs.

Since developing an effective supply chain structure is a cornerstone of SCM, this paper studies the relationship between supply chain attributes and operational performance in China. Based on relevant theories, we empirically examine three attributes that define a manufacturer's relationship with its upstream and downstream partners: location proximity, relationship continuity, and relative power over supply chain partners. Our study not only provides insights to Chinese manufacturers on how to design an effective supply chain system and improve efficiency, but our findings are also meaningful to foreign firms. For firms that pursue supply functions such as off-shoring production, outsourcing, and procurement in China, it is crucial to understand how upstream supply chain relationship influences operational performance. Echoing the recent trend of rediscovering China as a direct revenue-generating marketplace (Farrell 2004, Khana and Palepu 2006), we argue that it is of great importance to explore the operational connections between a manufacturer and its downstream customers in the value chain.

Besides examining the connection between supply chain attributes and a manufacturer's operational performance, we also investigate the relationship between inventory performance and profitability. Although the link between operations and finance has been studied extensively (Chen et al. 2005, Gaur et al. 2005, Rumyantsev and Netessine 2007a, 2007b, Cannon 2008, Capkun et al. 2009), to our best knowledge, this topic has not been discussed in the context of emerging markets. We aim to fill the void by exploring this relationship in China. Consistent with our consideration of both upstream and downstream supply chain relation- 
ships, we simultaneously estimate the effect of raw material and finished goods inventory on profitability. A comparison of our findings with those from previous research in developed countries provides important implications for managing companies with operations in China.

Using data collected by the World Bank, we examined 530 manufacturing companies in five industries in China. Compared with existing China-based empirical research, this dataset offers several advantages: the survey size is large and the response quality is good (gathered through face-to-face interviews); the survey items are primarily objective, and therefore, immune to potential self-report bias (Donaldson and Grant-Vallone 2002); and the survey contains detailed financial data. We propose hypotheses that relate supply chain attributes, inventory performance and financial profitability and test them. Managerial implications are given based on empirical results.

\section{Hypotheses}

In this section, we develop the hypotheses that describe the relationship between supply chain attributes and a manufacturer's operational performance, as well as the impact of the manufacturer's operational efficiency on its financial performance.

\section{$2.1 \quad$ Location proximity}

Location proximity has been identified as a key factor in establishing a close relationship between buyers and suppliers (Ford 1984, Goffin et al. 2006). Narasimhan and Nair (2005) argue that physical proximity implies a strong emphasis on the trust-based relationship between the supplier and the buyer aiming to enhance collaboration in supply chain operations. Initiatives like lean manufacturing (JIT) can be easily followed by the supply chain partners, 
resulting in reduction of inventory and subsequent increases in inventory turnover.

At the operational level, one obvious reason for proximity leading to higher inventory turnover is the reduced need for pipeline inventory (Zipkin 2000), and there are other direct and indirect ways in which proximity can reduce the need for safety stock. First, from the perspective of a buyer, a long distance results in long lead times in supply delivery, which would directly increase delivery uncertainty and hence require the buyer to hold more buffering inventory to hedge against the stock-out risk while awaiting replenishment (Zipkin 2000, Rumyantsev and Netessine 2007a). Second, indirectly, proximity contributes to information visibility (Wang and Wei 2007), enables information exchange, and reduces information asymmetry and monitoring costs (Dyer 1997), all of which could help reduce the need for safety stock through enhancing the accuracy and efficiency of forecasting, planning, and production scheduling. Third, proximity helps in solving problems more quickly, which also indirectly reduces the need for safety stock.

From the perspective of a supplier, proximity to customers reduces order processing cost and transportation cost, allowing the supplier to provide fast and frequent deliveries, and thus helps both firms to reduce cycle inventory, as suggested by classical inventory models like EOQ and fixed-time inventory models. Bhatnagar and Sohal (2005), using qualitative survey data, found that proximity to markets had a significant impact on supply chain competitiveness, measured by quality, flexibility, responsiveness and inventory turnover. Proximity, moreover, allows a manufacturer to respond quickly to changes in market conditions, providing greater adaptability to explore and use resources in their supply chains. Supply chain flexibility is enhanced by the tightness of supply chain relationships that develops when 
partners are in close proximity (Wang and Wei 2007).

The adverse effects of geographical distance on a manufacturer's performance can be intensified in China. Although the Chinese government has invested heavily in developing distribution infrastructure since joining the World Trade Organization, moving goods within China continues to be a challenge, due to China's sheer size (Zhao et al. 2006), as well as problems with insufficient infrastructure, government regulations, and regional protectionism (Jiang and Prater 2002). Because distribution is not yet free-market based and is still heavily controlled by large state-owned entities, acquiring products from farther away can be very inefficient. Underdeveloped telecommunication systems and warehousing facilities create additional barriers and challenges (Goh and Ling 2003). Such factors require customers to hold more buffer inventory against stock-out risk. In order to reduce their need to hold buffer inventories, customers may instead form partnerships with local manufacturers.

Considering both the operational impact on inventory policies and the nature of the transportation infrastructure, we propose the following hypotheses regarding the distance of a manufacturer to its supply chain partners:

H1a: The distance between a supplier and a manufacturer is inversely related to the manufacturer's raw material inventory turnover.

H2a: The distance between a customer and a manufacturer is inversely related to the manufacturer's finished goods inventory turnover. 


\subsection{Relationship continuity}

There is substantial theoretical support for the notion of relationship continuity as a factor in supply chain performance, primarily based on the premises of Transaction Cost Economics theory (TCE) (Williamson 1995). According to TCE, the most important factor in distinguishing between different types of performance is the existence of transaction-specific investments (TSIs) (Heide and John 1992), which are tangible and intangible assets that could not be easily redeployed if a supply chain relationship was terminated. The presence of TSIs in a supply chain encourages opportunistic behavior by suppliers and customers, such as demanding price concessions or sharing proprietary information with competitors. In order to create value in the relationship, manufacturers must provide appropriate safeguarding mechanisms, in order to eliminate the perceived risk of opportunistic behavior by suppliers and induce suppliers to make TSIs.

One of the most potent safeguards is the development of informal, relationship-oriented governance forms (Williamson 1995, Rindfleish and Heide 1997), including cooperative norms, which are the expectation of two parties to cooperate with each other (Heide and John 1992, Joshi and Campbell 2003). Relational governance is defined as the extent to which supply chain partners use mechanisms such as relational norms to maintain their relationships, based on common goals (Wang and Wei 2007). They are based on the expectation of relationship continuity, which regulates potential opportunistic behavior by a supply chain partner by casting the "shadow of the future" as a direct consequence of opportunism in the present (Joshi and Campbell 2003). Another important element of relational governance is commitment, which is an enduring desire to sustain a valued relationship (Wang and Wei 
2007, Joshi and Campbell 2003). TCE suggests that cooperative norms can be established only when there has been a history of interaction (Gundlach et al. 1995). Thus, relationship continuity is a norm facilitator, establishing the conditions necessary for cooperative norms to be established in a buyer-supplier relationship (Cai and Yang 2008).

Relational contracts are agreements in principle, based on recurrent transactions between parties that have a long-term relationship (Macneil 1980). Relationship continuity is essential for the establishment of trust and the development of relational contracts between supply chain members. In a collectivist culture like China (Hofstede, 1991), trust develops when a manufacturer repeatedly engages in supportive activities and provides assistance in times of need, over the course of a lengthy relationship (Yu and Liao 2008).

Information exchange may be limited in supply chains that are characterized by the threat of opportunism (Wang and Wei 2007). When supply chain partners have committed to a long term relationship, however, partners are more likely to devote effort and resources to the exchange of important information, including supply chain information. Thus, relationship continuity is related to the formation of social structures that facilitate access to resources, which increases information availability and exchange.

Long-term orientation is a key dimension of China's national culture, characterized by a preference for stability over change (Hofstede 1991). Long-term relationships with suppliers and customers foster guanxi networks among the trading partners. Guanxi is the Chinese system of personal connections, tied into long-term social obligations (Millington et al. 2006), and it can be an effective tool for supplier search and appraisal. Once a guanxi network has been established, Chinese supply chain partners are dedicated to maintaining a lasting 
relationship. This suggests that a long-term relationship with customers may be even more critical to performance in China than in Western countries.

Therefore, we propose the following hypotheses:

H1b: The length of its relationship with a supplier is positively related to a manufacturer's raw material inventory turnover.

H2b: The length of its relationship with a customer is positively related to a manufacturer's finished goods inventory turnover.

\subsection{Buyer-supplier power}

The relative influence of a manufacturer on its suppliers and customers may be a crucial factor in the manufacturer's performance. Generally speaking, its power over supply chain partners enables a manufacturer to acquire low-cost and high-quality inputs, as well as bargain for favorable contract terms with customers (Cox 2001, Cox et al. 2004). Greater power can also help the manufacturer to secure commitments from its supply chain partners and deter supply chain partners from behaving opportunistically in their transactions (Provan and Skinner 1989, Hawkins et al. 2008).

A manufacturer's control and leverage over its supply chain partners can enhance the manufacturer's inventory performance in several ways. A powerful manufacturer may be able to force its suppliers to hold higher levels of inventory on its behalf, which results in higher raw material inventory turnover for the manufacturer. It has been observed that powerful manufacturers tend to impose excess inventory on their suppliers, especially when the manufacturer implements JIT and lean operations (Hay 1987). Forcing its suppliers to carry superfluous stocks allows the manufacturer to hedge against its own schedule and order 
changes. Moreover, a powerful manufacturer may be capable of dumping excess inventory to its downstream customers, which results in enhanced finished goods inventory turnover for the manufacturer. In some cases, managers in powerful companies intentionally sell excess units of inventory to customers, in order to report higher sales and more favorable financial statements, which helps them get better pay for themselves, a phenomenon known as "channel stuffing" (Lai et al. 2009).

Buyer-supplier power can be particularly important in China's socioeconomic circumstances. An important element of China's national culture is its power distance (PD) (Hofstede 1991), which refers to the extent that less powerful members in an organization or society expect and accept that power is unequally distributed. In a high power distance national culture like China, power inequalities are acceptable (Hofstede 1991, Wang and Clegg 2002). People expect the more powerful party to make decisions (Randolph and Sashkin 2002). Therefore, we anticipate that the use of coercive power on supply chain partners may be prevalent in China, making the impact of a manufacturer's power on inventory performance significant.

In summary, we propose the following hypotheses:

H1c: A manufacturer's relative power over its suppliers is positively related to the manufacturer's raw material inventory turnover.

H2c: A manufacturer's relative power over its customers is positively related to the manufacturer's finished goods inventory turnover. 


\subsection{Relationship between operational and financial performances}

The turnover ratios of different inventory components (raw material, work-in-progress, and finished goods) are indicators of a manufacturer's operational efficiency at different stages of the manufacturing process. High performance in raw material inventory turnover suggests an efficient supply management and effective coordination between the procurement and production functions. High finished goods inventory turnover indicates that a manufacturer has managed a good customer relationship and is capable of matching demand with production.

Nevertheless, there is not a consensus about whether inventory performance is a robust indicator of a manufacturer's overall performance (Cannon 2008). Existing empirical studies provide some support for a positive relationship between inventory management and financial performance. Chen et al. (2005, 2007) found that manufacturers with abnormally high inventories had abnormally poor long-term stock returns, and Shah and Shin (2007)'s analysis of sector-level data showed that inventory performance is positively associated with financial performance. Demeter (2003), however, found that inventory improvement tends to influence manufacturer's profitability only indirectly.

There are different measures of financial performance. In this paper, we use return on sales (ROS), in line with Rumyantsev and Netessine (2007b). It enables us to compare our findings, based on data from China, with theirs from developed countries. Rumyantsev and Netessine (2007b) reported that both raw material and finished goods inventory turnover positively contributed to ROS. We hypothesize that a similar relationship exists for manufacturing companies in China:

H3: Both raw material and finished goods turnover are positively related to return on sales. 


\section{Methodology}

\subsection{Sample}

This study uses data from the Investment Climate Project (ICP) dataset collected by the World Bank. This project surveyed more than 50,000 firms in over 70 countries and collected detailed firm-level data on their investment climate. The China component of this survey was conducted as a joint effort with the Enterprise Survey Organization of the National Statistics Bureau of China. The sections on relationships with supply chain partners include a number of items about the location and number of suppliers and customers, and the length of relationship with them. Two waves of surveys were administered in 23 cities, with 100-150 randomly selected firms in each city, stratified by firm size and industry. Data was gathered using face-to-face interviews with general managers, managing directors, and accounting, operations, and human resource managers. Each section was administrated to the manager who possessed the best knowledge about the corresponding questions. For example, the demographic information section was administrated to general managers, while the section on supply chain partner relationships was administered to the chief operations manager or managing director. Data entry followed strict protocols.

We had access to a subset of the China dataset, containing 895 firms in 8 cities (Haerbin, Changchun, Benxi, Dalian, Hangzhou, Wenzhou, Zhengzhou, and Nanchang). We eliminated firms in the service, agriculture, wholesale, and retail sectors, leaving data from 530 manufacturing firms in five industries (see Table 1). The average age of the sampled firms was 15 years, indicating that most of the firms were formed after China's economic reform. The firms, on average, had 458 employees, suggesting that they are mostly mid- to large- 
sized. Most of the firms were private (73\%), with state-owned firms accounting for $15 \%$ of the sample, and foreign or joint ventures around $12 \%$.

\subsection{Model and measurement}

To test hypotheses $\mathrm{H} 1$ and H2, we estimated the following regression equations:

$$
\begin{aligned}
& \log D I R_{i j c}=\alpha+\beta_{1} L O C_{i j c}^{S}+\beta_{2} R E L_{i j c}^{S}+\beta_{3} P O W E R_{i j c}^{S}+\beta_{4} X_{i j c}+\mu_{j}+\nu_{c}+\varepsilon_{i j c} \\
& \log D I F_{i j c}=\alpha+\beta_{1} L O C_{i j c}^{C}+\beta_{2} R E L_{i j c}^{C}+\beta_{3} P O W E R_{i j c}^{C}+\beta_{4} X_{i j c}+\mu_{j}+\nu_{c}+\varepsilon_{i j c}
\end{aligned}
$$

$\log D I R_{i j c}$ and $\log D I F_{i j c}$ denote the logarithm of average days of raw material $(D I R)$ and finished goods inventories $(D I F)$, respectively. In line with Rumyantsev and Netessine (2007b), we use average days of inventory to measure inventory performance, while average days of inventory are 365 days/ inventory turnover. ${ }^{1}$ Subscripts $i j c$ indicates firm $i$, industry $j$, and city $c$.

$L O C$ represents location proximity, with superscripts $S$ and $C$ indicating the proximity of suppliers and customers, respectively. In the survey, each firm was first asked to report the total number of suppliers of the raw materials that it spent the most money on and regularly purchased from, as well as the total number of customers for the products in its main business line. Then, the firm was asked to "give the percentage of its suppliers and customers in the following categories: within the same district as the firm, outside that district but within the same city, outside that city but within the same province, outside that province but in China, and outside of China." The total percentage adds up to $100 \%$ for

\footnotetext{
${ }^{1}$ Raw material inventory turnover was calculated as the ratio of the cost of direct materials to the yearly average raw material inventory, and finished goods inventory turnover the ratio of the cost of goods sold to yearly finished goods inventory. The yearly average inventory is the mean of the inventory levels at the beginning and the end of the accounting year.
} 
each firm. In the estimation model, in order to avoid perfect multicollinearity, the percentage for one category (in our case, "within the same district") was left out. The estimate of $\beta_{1}$ indicates the percentage change of $D I R / D I F$ associated with a one percentage point increase in the percent of suppliers/customers located in a category, while holding the percentages for the other three location categories constant.

$R E L^{S}$ and $R E L^{C}$ denote the length of the relationship with suppliers (S) and customers (C). Questions in the survey asked "on average, how long has the firm done business with major suppliers of the most costly non-labor inputs?" and "on average, how long has the firm done business with clients in their main business line?" The firm chose the answer from one of the following five categories: less than 1 year, 1-2 years, 2-3 years, 3-4 years, and 4 years or more. The variable, $R E L$, takes five values from 1 to 5 , corresponding to the five categories.

$P O W E R^{S}$ and $P O W E R^{C}$ are two sets of variables representing the manufacturer's power over its suppliers (S) and customers (C). Cox (2001) suggests that the relative power between a buyer and a supplier may be characterized by the number of each party, percentage of shares of one party's business controlled by the other party, availability of alternatives in the market, and buyer/supplier's switching and searching cost for alternatives. We used the percentage of inputs from the largest supplier and the number of suppliers to measure the manufacturer's relative power over its suppliers, and we used the percent of total sales that goes to the largest customer and the number of customers to indicate the manufacturer's relative power over its customers. These variables are commonly used to measure manufacturers' power over supply chain partners in the literature (Nagarajan and Bassok 
2008, Fabbi and Klapper 2008, Tsuruta, 2009, Giannetti et al. 2009). The larger percentage of inputs that comes from a single supplier implies that a manufacturer's input is more heavily controlled by the main supplier, which enhances the manufacturer's dependency on the supplier and reduces its power. A large number of suppliers, on the other hand, reduces the manufacturer's dependency on a specific supplier and results in greater power over its suppliers. By analogy, a greater percentage of sales going to the largest customer and a smaller number of customers suggest that the manufacturer's business is heavily controlled by a few main customers, resulting in weaker power over its customers.

$X$ 's refer to a set of variables in regressions (1) and (2) that control for other manufacturers' characteristics, including the age of manufacturers, employment size, dummy variables indicating whether the manufacturer is state-owned or foreign-owned and joint venture (with the default category being privately owned), and the manufacturer's gross margin. Gross margin is calculated as the difference between sales and costs of goods sold divided by sales. We also controlled for industry and city fixed effects, denoted by $\mu_{j}$ and $\nu_{c}$.

To test hypothesis H3, the impact of inventory turnover on financial performance, we estimated the following equation:

$R O S_{i j c}=\alpha+\beta_{1} \log D I R_{i j c}+\beta_{2} \log D I F_{i j c}+\beta_{3} \log D A P_{i j c}+\beta_{4} \log D A R_{i j c}+\beta_{5} X_{i j c}+\mu_{j}+\nu_{c}+\varepsilon_{i j c}$

Return on sales (ROS) was calculated as the ratio of net income to total sales. $\log D A P$ and $\log D A R$ denote the logarithm of days of accounts payable and accounts receivable. Because detailed financial statement information for calculating $D A P$ and $D A R$ was not available for the surveyed manufacturers, we instead based these variables on the two questions in the 
survey which asked "the average number of days before the manufacturer pays off credits (DAP)" and "the average number of days before the manufacturer receives the actual payment (DAR)." X's are the set of variables used to control for manufacturers' characteristics. These are the same as those in regressions (1) and (2), except for the exclusion of gross margin. Regression (3) is specified as close to that in Rumyantsev and Netessine (2007b) as possible, to enable comparison between our results and theirs. Similar to regressions (1) and (2), industry and city fixed effects are included in model (3).

\section{Analysis}

\subsection{Descriptive results}

Table 1 summarizes the performance measures. The median DIR and DIF were 58.99 and 44.49 days, respectively. Our results show that the inventory performance of Chinese manufacturers is considerably worse than that of manufacturers in developed countries (in Rumyantsev \& Netessine 2007b, the median value for DIR and DIF was 16 and 34 days). Electronics and automotive manufacturers outperformed the other industries, with average ROS around $10 \%$.

Table 2 reports descriptive statistics for the independent variables. Upstream supply chain attributes are shown in Panel A of Table 2. The majority of the manufacturers have traded with their main suppliers for more than 4 years, while those having a relationship with suppliers for two or fewer years accounted for a very small fraction of the sample. This pattern was robust across industries and reflects a general long-term tendency in suppliermanufacturer relationships. Bhatnagar and Sohal (2005) reported a similar pattern for 
companies in Singapore, Japan, Malaysia, Indonesia and North America. Cross-industry comparison revealed that automotive manufacturers have a longer relationship with their main suppliers than manufacturers in other industries. In terms of geographic proximity, Table 2 displays the average percentage of suppliers in each of the categories, calculated across the manufacturers, and it was the largest for the categories in which suppliers are located in the same city as the manufacturer and suppliers are from outside the manufacturer's province but still within China. The average number of suppliers was slightly less than 40 per manufacturer, with noticeable variation across industries. On average, the manufacturers acquired $60 \%$ of inputs from their largest supplier, suggesting that the manufacturers were rather heavily dependent on their main supplier. This result showed little variation across industries.

Similar patterns were observed for downstream supply chain attributes (Panel B in Table 2). There was a tendency toward long relationships with customers; roughly 70 percent of the manufacturers have had a 4-year or longer relationship with their main customers, and most customers reside in the same city as the manufacturer or in other province. The average number of customers was 125, significantly greater than the average number of suppliers. Electronics manufacturers and food processing companies had very large customer bases, with more than 200 customers on average. The average percentage of sales that goes to the largest customer was $37 \%$ across manufacturers, with this value being lowest for food manufacturers and highest for automotive manufacturers.

Table 3 shows Pearson inter-correlation coefficient estimates for main independent and dependent variables. Most of the estimates were relatively low, however a few variables 
exhibited higher correlations. The significant negative correlations between location variables were not surprising and of no concern to the estimation, as their sum is a constant 100. For H3, $\log$ DIR and LogDIF were strongly correlated (0.570), and $\log \mathrm{DAP}$ and $\log \mathrm{DAR}$ were significantly correlated (0.238). In order to control for multicollinearity in the regression analysis, we estimated alternative models to assess the robustness of our results. Section 4.2.3 provides the details of our robustness test.

\subsection{Regression results}

We report the results for regression models (1)-(3) in this subsection. To reduce the influence of outliers, we winsorized the inventory measures at the top and bottom 2.5 percent level of the distribution.

\subsubsection{Upstream relationships}

Table 4 provides the regression results for equation (1). Our results support H1a and suggest the importance of location proximity to inventory performance. We conducted a joint test on location variables. The F-test reveals that location variables are jointly significant at the $10 \%$ level. With respect to a specific location variable, for example, for the "overseas" category, the estimate suggests that holding the percentage of suppliers in other location categories constant, a one percentage point increase in the percent of oversea suppliers is associated with a $1.3 \%$ increase in DIR, while a one percentage point increase in the suppliers within the same province is related to a $0.8 \%$ increase in DIR. This result suggests that having more remote suppliers leads to worse inventory performance.

H1b was also strongly supported. The length of relationship with suppliers was negatively 
related to DIR, and the coefficient estimate was statistically significant. This suggests that a longer relationship with suppliers is beneficial to manufacturers, in terms of improving raw material inventory turnover. We also conduct a robust test by changing the length of supplier relationship into five categorical variables. The regression results did not vary.

Hypothesis H1c indicated that the manufacturers' relative power over their suppliers would be negatively related to DIR. The results in Table 4 partially supported H1c, as the share of supplies from the largest suppliers had a significantly positive effect on DIR but the number of suppliers was statistically insignificant. The greater share of inputs from the largest supplier implies a stronger dependency on the supplier and hence relatively weaker power over the supplier. Thus, this estimate supports the notion that stronger power over suppliers could bring lower DIR and higher inventory turnover.

Table 4 also documents the effect of a manufacturer's age, employment size, ownership and gross margin on DIR. Consistent with Gaur et al. (2005), we found that gross margin was positively related to DIR, supporting their view that managers tend to trade off inventory turns and gross margin in their decision making. Older manufacturers had a larger DIR than the newer manufacturers. One possible explanation is that newer manufacturers are more likely to take advantage of technology to streamline their supply chain operations, while older manufacturers are subject to organizational and technical inertia. We also observed that manufacturers with a larger number of employees had better inventory performance.

\subsubsection{Downstream relationships}

Table 5 reports the regression estimates for equation (2), exhibiting similar patterns to the results for the upstream model. We found that the location of customers was significantly 
related to finished goods inventory turnover, with the joint test of location variables significant at the 1 percent level. Within China, a greater percentage of customers located farther away from the manufacturer was associated with an increase in DIF. However, when the percentage of overseas customers increases, inventory turnover performance is better, but the estimate is insignificant. Based on these results, we concluded that H2a was partially supported. $^{2}$ The length of relationship with the main customers was negatively related to DIF, and the alternative model, with relationship length broken into categorical variables, also supported the predictions of $\mathrm{H} 2 \mathrm{~b}$. This suggests that a long-term business relationship with customers could also benefit the manufacturer by lowering DIF, just as a long-term relationship with suppliers does. H2c was not supported; the coefficient estimates for the share of sales going to the largest customer and the number of customers were statistically insignificant.

Similar to the observations for upstream relationship, we found from Table 5 that gross margin had a positive impact on DIF, which again confirms Guar et al. (2005). Moreover, newer and larger manufacturers tend to have better finished goods inventory performance. Compared with private firms, foreign and joint venture firms have a significantly lower DIF, suggesting that Chinese companies, on average, are not as efficient as their foreign competitors.

\footnotetext{
${ }^{2}$ We further examined whether location proxmity to customers affect the finisehd goods inventory turnover ratio through the denominator (inventory levels) or numerator (costs of goods sold). we found that promixty led to greater inventory turnover mostly through the denominator, specifically better inventory control and lower inventory levels.
} 


\subsubsection{Relationship between operational and financial performance}

Table 6 reports the results for regression model (3). Hypothesis H3 was clearly supported, as both DIR and DIF were significantly negatively related to ROS. More interestingly, we observe that the impact of DIF on ROS was stronger than that of DIR. Our estimates came very close to those reported for France and the Netherlands by Rumyantsev and Netessine (2007b), who found that both raw material and finished goods inventory turnover were significantly related to ROS and that DIF was a more important factor to profitability than DIR. For manufacturers in Canada, Germany, and the U.S., only raw material inventory turnover significantly impacted ROS, while in Switzerland and placeGreat Britain, neither raw material nor finished goods inventory turnover was significantly related to ROS. The above comparison suggests that, in China, both upstream and downstream inventory turnover is crucial to a manufacturer's financial performance, just as in France and the Netherlands. Moreover, inventory turnover is more important to a manufacturer's profitability in China than in some developed countries such as Switzerland and placeGreat Britain.

We went beyond Rumyantsev and Netessine (2007b) by estimating the effect of DIR and DIF on ROS for each industry separately. The results varied considerably by industry. For machinery and automotive manufacturers, DIF had a larger effect on ROS than DIR. However, for apparel and electronics manufacturers, the results were reversed - DIR was more related to profitability.

Similar to Rumyantsev and Netessine (2007b), we also included DAP and DAR as explanatory variables in regression model (3). The results were as expected - DAP was positively associated with ROS, while DAR was negatively associated with ROS; however the 
estimate for DAR was insignificant. The magnitude of the estimates was similar to that reported in Rumyantsev and Netessine (2007b). We also note that, among the control variables, only company age was statistically significant, and it was negatively correlated with ROS, particularly in the apparel and electronics industries.

As shown in the correlation table, DIR and DIF were significantly correlated, as were DAP and DAR. To alleviate the multicollinearity problem and test robustness of the results, we estimated alternative models, including DIR and DIF one at a time (similarly, DAP and DAR one at a time). The results did not vary. For brevity, these results are not reported but available from the authors upon request.

\section{Conclusions}

With a primary focus on manufacturing operations in China, this paper aims to explain how supply chain attributes influence operational performance and how operational performance, in turn, affects profitability. We found a number of relationships that are important to Chinese manufacturers, with managerial implications that could be valuable for both operations managers in China and those who use supply chains that flow through China.

First, the operational efficiency of Chinese companies is relatively low, in comparison with companies in developed countries or those owned by foreign investors. The average days of raw material and finished goods inventory were significantly higher than those reported in developed countries. On one hand, it is disappointing to learn about this gap; on the other hand, it points out a potential opportunity for Chinese manufacturers to improve. Second, our study is among the first in China to carry out comprehensive evaluation of supply 
chain characteristics affecting inventory turnover and provide empirical evidence. The three supply chain attributes that we have examined, specifically location proximity to suppliers and customers, the length of relationship with them, and their relative power over them all had a significant impact on the manufacturer's inventory turnover. Our findings suggest that, when Chinese operational managers engage in supply chain design and management, these attributes should be given careful consideration, in order to optimize inventory performance. Third, we found that, in China, both upstream and downstream inventory improvement contributes significantly to the manufacturer's profitability. The linkage between inventory turnover and financial performance is even stronger in China, compared to several developed countries. This conveys an important message to Chinese practitioners that they should pay special attention to inventory performance, as it is critical to the manufacturer's bottom-line profitability.

From an academic perspective, our main contribution lies in supplementing the existing empirical literature that has been predominated by studies of developed countries. Our research is based on China, a vast and fast-growing developing country. We verified that several empirical relationships found in developed countries still hold in China, but also pointed out several unique aspects about supply chains in China. For example, location proximity of supply chain partners is necessary, due to under-developed transportation infrastructure and regional protectionism. Related to China's cultural emphasis on long-term orientation, manufacturers benefit from longer relationships with their key supply chain partners.

Our study has certain limitations, and addressing them gives rise to future research opportunities. For example, most existing inventory performance analysis is based on ac- 
counting reports (panel data) and provides interesting dynamic results over long run, while our paper estimates a static model, based on the available data. It would be interesting to investigate the dynamic interactions between the important elements of our model. With this paper, we hope to initiate more structural studies of operational issues, as well as inspire future studies carrying out more analysis on developing countries.

\section{References}

Bhatnagar, R., A. S. Sohal. 2005. Supply chain competitiveness: Measuring the impact of location factors, uncertainty and manufacturing practices. Technovation, 25 (5), 443-456.

Cai, S., Z. Yang. 2008. Development of cooperative norms in the buyer-supplier relationship: The Chinese experience. Journal of Supply Chain Management, 44 (1), 55-70.

Cannon, A. R. 2008. Inventory improvement and financial performance. International Journal of Production Economics, 115 (2), 581-593.

Capkun, V., A. Hameri, L. A. Weiss. 2009. On the relationship between inventory and financial performance in manufacturing companies. International Journal of Operations \& Production Management, 29(8), 789-806.

Chen, H., M. Frank, O. Wu. 2005. What actually happened to the inventories of American companies between 1981 and 2000? Management Science, 51(7), 1015-1031.

Chen, H., M. Frank, O. Wu. 2007. US retail and wholesale inventory performance from 1981 to 2003. Manufacturing \& Service Operations Management, 9 (4), 430-456.

Cox, A. 2001. Understanding buyer and supplier power: A framework for procurement and supply competence. Journal of Supply Chain Management, 37 (2), 8-15.

Cox, A., G. Watson, C. Lonsdale, J. Sanderson. 2004. Managing appropriately in power regimes: Relationship and performance management in 12 supply chain cases. Supply Chain Management: An International Journal, 9 (5), 357-371.

Demeter, K. 2003. Manufacturing strategy and competitiveness. International Journal of Production Economics, 81-82, 205-213. 
Donaldson, S. I., E. J. Grant-Vallone. 2002. Understanding self-report bias in organizational behavior research. Journal of Business and Psychology, 17(2), 245-260.

Dyer, J. H. 1997. Effective interfirm collaboration: How firms minimize transaction costs and maximize transaction value. Strategic Management Journal, 18 (7), 535-556.

Fabbri, D., L. F. Klapper. 2008. Trade credit supply, market power and matching of trade credit terms. Working paper, University of Lausanne, Lausanne, Switzerland.

Farrell, D. 2004. Beyond offshoring: Assess your company's global potential. Harvard Business Review, December.

Ford, D. 1984. Buyer/seller relationships in international industrial markets. Industrial Marketing Management, 13 (2), 101-112.

Gaur, V., M. L. Fisher, A. Raman. 2005. An econometric analysis of inventory turnover performance in retail services. Management Science, 51 (2), 181-194.

Giannetti, M., M. Burkart, T. Ellingsen. 2009. What you sell is what you lend? Explaining trade credit contracts. Review of Financial Studies, forthcoming.

Goffin, K., F. Lemke, M. Szwejczewski. 2006. An exploratory study of "close" suppliermanufacturer relationships. Journal of Operations Management, 24 (2), 189-209.

Goh, M., C. Ling. 2003. Logistics development in China. International Journal of Physical Distribution $\mathscr{G}$ Logistics Management, 33 (10), 896-917.

Gundlach, G., R. Schrol, J. Mentzer. 1995. The structure of commitment in exchange. Journal of Marketing, 59 (1), 78-92.

Heide, J. B., G. John. 1992. Do norms matter in marketing relationships? Journal of Marketing, 56 (2), 32-44.

Hawkins, T. G., C. M. Wittmann, M. M. Beyerlein. 2008. Antecedents and consequences of opportunism in buyer-supplier relations: Research synthesis and new frontiers. Industrial Marketing Management, 37 (8), 895-909.

Hay, E. J. 1987. Will the real just-in-time purchasing please stand up? In: Just-in-Time Reprints, American Production and Inventory Control Society, Falls Church, StateVA. 
Hofstede, G. 1991. Cultures and Organizations: Software of the Mind. McGraw-Hill, London.

Jiang, B., E. Prater. 2002. Distribution and logistics development in China: The revolution has begun. International Journal of Physical Distribution 8 Logistics Management, 32(9), 783-798.

Joshi, A. W., A. J. Campbell. 2003. Effect of environmental dynamism on relational governance in manufacturer-supplier relationships: A contingency framework and an empirical test. Journal of the Marketing Science, 31 (2), 176-188.

Khana, T., K., G. Palepu. 2006. Emerging giants: building world-class companies in developing countries. Harvard Business Review, October.

Lai, G. M., L. Debo, L. Nan. 2009. Manager incentives for channel stuffing with market-based compensation. Working paper, Carnegie Mellon University, Pittsburgh, StatePA.

Macneil, placeI. R. 1980. The New Social Contract. Yale University Press, New Haven.

placeCityMillington, A., M. Eberhardt, B. Wilkinson. 2006. Guanxi and supplier search mechanisms in China. Human Relations, 59 (4), 505-531.

Nagarajan, M., Y. Bassok, 2008. A bargaining framework in supply chains: the assembly problem. Management Science, 54(8), 1482-1496.

Narasimhan, R., A. Nair. 2005. The antecedent role of quality, information sharing and supply chain proximity on strategic alliance formation and performance. International Journal of Production Economics, 96 (3), 301-313.

Provan, K. G., S. J. Skinner. 1989. Interorganizational dependence and control as predictors of opportunism in dealer-supplier relations. Academy of Management Journal, 32 (1), 202212.

Randolph, W. A., M. Sashkin. 2002. Can organizational empowerment work in a multinational setting? Academy of Management Executive, 16 (1), 102-115.

Rindfleisch, A., J. B. Heide. 1997. Transaction cost analysis: Past, present, and future applications. Journal of Marketing, 61 (4), 30-54. 
Rumyantsev, S., S. Netessine. 02007a. What can be learned from classical inventory models? A cross-industry exploratory investigation. Manufacturing $\&$ Service Operations Management, 9(4), 409-429.

Rumyantsev, S., S. Netessine. 2007b. Inventory and its relationship with profitability: Evidence for an international sample of countries. Working paper, University of Pennsylvania, Philadelphia, PA.

Shah, R., H. Shin. 2007. Relationships among information technology, inventory, and profitability: An investigation of level invariance using sector level data. Journal of Operations Management, 25 (4), 768-784.

Tsuruta, D. 2009. Customer relationships and the provision of trade credit during a recession. Working paper, National Graduate Institute for Policy Studies, Tokyo, Japan.

Wang, E. T. G., H. L. Wei. 2007. Interorganizational governance value creation: Coordinating for information visibility and flexibility in supply chains. Decision Sciences, 38 (4), 647674.

Wang, K. Y., placeS. Clegg. 2002. Trust and decision making: are managers different in the People's Republic of China and in Australia? Cross-Cultural Management, 9 (1), 30-45.

Williamson, O.E. 1995. Transaction cost economics and organization theory. In O.E. Williamson (Ed.) Organization theory: from Chester Barnard to the present and beyond. New York: Oxford University Press, 207-256.

Yu, C., R. Liao. 2008. The impact of governance mechanisms on transaction-specific investments in supplier-manufacturer relationships: A comparison of local and foreign manufacturers. Management International Review, 48(1), 95-114.

Zhao, X.., B. Flynn, A. Roth. 2006. Decision sciences research in China: A critical review and research agenda - foundations and overview. Decision Sciences, 37(4), 451-497.

Zhao, X., B. Flynn, A. Roth. 2007. Decision science research in China: Current status, opportunities, and propositions for research in supply chain management, logistics, and quality management. Decision Sciences, 38 (1), 39-80.

Zipkin, P. 2000. Foundations of Inventory Management. McGraw-Hill, New York. 


\section{Tables}

Table 1. Demographics and performance measure for sample plants

\begin{tabular}{|c|c|c|c|c|c|c|}
\hline \multicolumn{7}{|l|}{ Demographics for sample plants } \\
\hline & $\begin{array}{c}\text { All } \\
(n=530)\end{array}$ & $\begin{array}{l}\text { Apparel } \\
(\mathrm{n}=141)\end{array}$ & $\begin{array}{l}\text { Electronics } \\
(\mathrm{n}=144)\end{array}$ & $\begin{array}{l}\text { Automotive } \\
(\mathrm{n}=120)\end{array}$ & $\begin{array}{l}\text { Machinery } \\
\quad(\mathrm{n}=94)\end{array}$ & $\begin{array}{c}\text { Food } \\
(\mathrm{n}=31)\end{array}$ \\
\hline Haerbin & 94 & 17 & 40 & 28 & 9 & 0 \\
\hline Changchun & 92 & 16 & 10 & 32 & 30 & 4 \\
\hline Benxi & 51 & 9 & 0 & 1 & 35 & 6 \\
\hline Dalian & 43 & 11 & 16 & 12 & 3 & 1 \\
\hline Hangzhou & 62 & 13 & 28 & 17 & 4 & 0 \\
\hline Wenzhou & 63 & 15 & 30 & 11 & 7 & 0 \\
\hline Zhengzhou & 38 & 31 & 6 & 0 & 0 & 1 \\
\hline Nanchang & 87 & 29 & 14 & 19 & 6 & 19 \\
\hline \multicolumn{7}{|l|}{ Descriptive statistics } \\
\hline & $\begin{array}{c}\text { All } \\
(n=530)\end{array}$ & $\begin{array}{l}\text { Apparel } \\
(\mathrm{n}=141)\end{array}$ & $\begin{array}{l}\text { Electronics } \\
\quad(\mathrm{n}=144)\end{array}$ & $\begin{array}{l}\text { Automotive } \\
(\mathrm{n}=120)\end{array}$ & $\begin{array}{l}\text { Machinery } \\
\quad(\mathrm{n}=94)\end{array}$ & $\begin{array}{c}\text { Food } \\
(\mathrm{n}=31)\end{array}$ \\
\hline Age of firm & 15.46 & 14.70 & 15.14 & 16.48 & 14.57 & 19.16 \\
\hline Employment size (in hundred) & 4.58 & 3.46 & 3.71 & 7.47 & 4.42 & 3.07 \\
\hline \multicolumn{7}{|l|}{ Ownership (percentage) } \\
\hline State-owned & 15.28 & 7.09 & 17.36 & 15.83 & 19.15 & 29.03 \\
\hline Foreign-owned or joint venture & 11.89 & 9.22 & 11.81 & 17.50 & 9.57 & 9.68 \\
\hline Private & 72.83 & 83.69 & 70.83 & 66.67 & 71.28 & 61.29 \\
\hline Sales (million yuan) & 209.35 & 57.69 & 196.77 & 551.99 & 72.51 & 46.19 \\
\hline Net income (million yuan) & 42.14 & 4.82 & 30.31 & 139.04 & 4.07 & 7.25 \\
\hline Return on sales (ROS) $^{\dagger}$ & 0.072 & 0.038 & 0.101 & 0.094 & 0.044 & 0.077 \\
\hline Cost of direct materials (million yuan) & 82.69 & 31.38 & 116.85 & 164.88 & 28.92 & 19.02 \\
\hline Cost of goods sold (million yuan) & 165.28 & 49.95 & 159.92 & 433.27 & 48.26 & 32.21 \\
\hline Gross margin $^{\dagger}$ & 0.161 & 0.091 & 0.181 & 0.182 & 0.151 & 0.252 \\
\hline \multicolumn{7}{|l|}{ Inventory (million yuan) } \\
\hline Raw material & 7.94 & 3.46 & 11.68 & 12.43 & 3.86 & 3.21 \\
\hline Finished goods & 11.31 & 3.24 & 16.33 & 21.61 & 5.14 & 2.08 \\
\hline \multicolumn{7}{|l|}{ Days of inventory ${ }^{\dagger}$} \\
\hline Raw material & 58.99 & 43.69 & 71.02 & 45.20 & 90.11 & 51.66 \\
\hline Finished goods & 44.49 & 25.87 & 56.10 & 43.93 & 57.64 & 32.15 \\
\hline Days of accounts payable & 18.4 & 15.9 & 21.1 & 18.3 & 21.3 & 8.1 \\
\hline Days of accounts receivable & 24.7 & 15.8 & 35.7 & 23.7 & 23.7 & 16.7 \\
\hline
\end{tabular}

${ }^{\dagger}$ Median is reported for ratio value. 
Table 2. Descriptive results for independent variables

\section{$\underline{\text { Panel A }}$}

Location proximity of suppliers

Within the same district (\%)

Within the same city (\%)

Within the same province (\%)

Not same province in China (\%)

Overseas (\%)

Length of relationship with suppliers

Less than 1 year

All
$(n=530)$

Apparel

Electronics

Automotive
$(n=120)$

$\begin{array}{cc}\text { Machinery } & \text { Food } \\ (\mathrm{n}=94) & (\mathrm{n}=31)\end{array}$

1-2 years

$\begin{array}{ccc}\% & \% & \% \\ 13.91 & 11.65 & 12.22\end{array}$

$\%$
14.53
19.58
16.29
41.79
7.80
$\%$

$\%$

$\%$

23.99

23.51

22.74

13.41

16.23

17.12

43.24

6.45

40.67

8.39

$\%$

1.39

1.67

4.86

2-3 years

4.53

5.67

15.97

0.83

10.00

17.36

9.17

60.42

78.33

53.36

36.78

17.48

18.79

$31.03 \quad 27.62$

$16.84 \quad 23.24$

$31.79 \quad 30.00$

Greater than 4 years

65.28

65.25

37.5

29.21

64.86

64.69

2.86

0.35

$\%$

$\%$

3.19

7.45

0

60.06

51.58

9.57

6.45

16.13

21.28

19.35

58.51

58.06

Share of supplies from the largest supplier (\%)

\section{$\underline{\text { Panel B }}$}

Location proximity of customers

Within the same district (\%)

Within the same city (\%)

Within the same province (\%)

Not same province in China (\%)

Overseas (\%)

Length of relationship with customers

Less than 1 year

1-2 years

2-3 years

3-4 years

Greater than 4 years

\section{$\%$}

13.87

22.01

16.55

33.10

14.47

$\%$

3.58

6.98

11.32

9.43

68.68

125.12

36.62

\section{$\%$}

11.59

22.57

14.94

14.74

36.16

$\%$

5.67

5.67

13.48

11.35

63.83

60.74

41.49
$\%$

7.67

17.59

17.74

44.45

12.54

$\%$

4.17

7.64

10.42

10.42

67.36

230.77

30.99

$\%$
22.87
18.76
10.99
41.88
5.49
$\%$

17.72

64.29

61.46

55.14

Share of sales to the largest customer (\%) 
Table 3. Correlation matrix

\begin{tabular}{|c|c|c|c|c|c|c|c|c|c|c|c|}
\hline \multicolumn{3}{|c|}{ Panel A } & 1 & 2 & 3 & 4 & 5 & 6 & 7 & 8 & 9 \\
\hline 1 & \multicolumn{2}{|l|}{ Log DIR } & 1.000 & & & & & & & & \\
\hline \multicolumn{2}{|l|}{2} & Within the same district & -0.050 & 1.000 & & & & & & & \\
\hline 3 & Location & Within the same city & 0.038 & $-0.203^{* * *}$ & 1.000 & & & & & & \\
\hline 4 & proximity to & Within the same province & 0.022 & $-0.209 * * *$ & $-0.188^{* * *}$ & 1.000 & & & & & \\
\hline 5 & suppliers & In China & -0.041 & $-0.398 * * *$ & $-0.499 * * *$ & $-0.239 * * *$ & 1.000 & & & & \\
\hline \multicolumn{2}{|l|}{6} & Overseas & 0.051 & $-0.147^{* * *}$ & $-0.218^{* * *}$ & $-0.164 * * *$ & $-0.124 * * *$ & 1.000 & & & \\
\hline 7 & \multicolumn{2}{|c|}{ Length of relationship with suppliers } & -0.062 & $-0.073 *$ & -0.039 & 0.015 & 0.046 & $0.068 *$ & 1.000 & & \\
\hline 8 & \multicolumn{2}{|c|}{ Number of suppliers } & -0.005 & 0.004 & -0.030 & 0.005 & 0.036 & -0.028 & $0.078^{*}$ & 1.000 & \\
\hline 9 & \multicolumn{2}{|c|}{ Share of supplies from the largest supplier } & $0.157^{* * *}$ & 0.018 & $-0.080 *$ & -0.062 & 0.050 & $0.079 *$ & 0.029 & $-0.088^{*}$ & 1.000 \\
\hline \multicolumn{3}{|c|}{ Panel B } & 1 & 2 & 3 & 4 & 5 & 6 & 7 & 8 & 9 \\
\hline 1 & \multicolumn{2}{|l|}{ Log DIF } & 1.000 & & & & & & & & \\
\hline \multicolumn{2}{|l|}{2} & Within the same district & -0.051 & 1.000 & & & & & & & \\
\hline 3 & \multirow{4}{*}{$\begin{array}{l}\text { Location } \\
\text { proximity to } \\
\text { customers }\end{array}$} & Within the same city & $0.108 * *$ & $-0.167 * * *$ & 1.000 & & & & & & \\
\hline 4 & & Within the same province & $0.138 * * *$ & $-0.191 * * *$ & $-0.119 * * *$ & 1.000 & & & & & \\
\hline 5 & & In China & $0.127 * * *$ & $-0.347 * * *$ & $-0.417 * * *$ & $-0.191 * * *$ & 1.000 & & & & \\
\hline 6 & & Overseas & $-0.301 * * *$ & $-0.223^{* * *}$ & $-0.287 * * *$ & $-0.271 * * *$ & $-0.247 * * *$ & 1.000 & & & \\
\hline 7 & \multicolumn{2}{|c|}{ Length of relationship with customers } & -0.072 & 0.030 & -0.025 & $-0.083 * *$ & 0.014 & 0.047 & 1.000 & & \\
\hline 8 & \multicolumn{2}{|c|}{ Number of customers } & -0.064 & $-0.067 *$ & -0.019 & -0.011 & $0.114 * * *$ & -0.040 & -0.003 & 1.000 & \\
\hline 9 & \multicolumn{2}{|c|}{ Share of sales to the largest customer } & $-0.090 *$ & $0.142^{* * *}$ & 0.037 & $-0.069 *$ & $-0.217 * * *$ & $0.127 * * *$ & $0.139 * * *$ & $-0.163 * * *$ & 1.000 \\
\hline \multicolumn{3}{|c|}{ Panel C } & 1 & 2 & 3 & 4 & 5 & & & & \\
\hline 1 & \multicolumn{2}{|l|}{ ROS } & 1.000 & & & & & & & & \\
\hline 2 & \multicolumn{2}{|l|}{ Log DIR } & $-0.253 * * *$ & 1.000 & & & & & & & \\
\hline 3 & \multicolumn{2}{|l|}{ Log DIF } & $-0.316^{* * *}$ & $0.570 * * *$ & 1.000 & & & & & & \\
\hline 4 & \multicolumn{2}{|l|}{ Log DAP } & $0.081^{* *}$ & -0.038 & -0.075 & 1.000 & & & & & \\
\hline 5 & \multicolumn{2}{|l|}{ Log DAR } & 0.041 & -0.024 & -0.011 & $0.238 * * *$ & 1.000 & & & & \\
\hline
\end{tabular}


Table 4. Regression results, Hypotheses 1a-1c

Dependent variable:

Log DIR

Upstream supply chain attributes

Coefficient estimates

$t$-value

Location proximity of suppliers

Within the same district (\%)

Within the same city (\%)

0.006

Within the same province (\%)

0.008

$2.00 * *$

Not same province in China (\%)

0.003

1.05

Overseas (\%)

0.014

$3.08 * * *$

Length of relationship with suppliers

$-0.133$

$-1.82 *$

Relative power over suppliers

Number of suppliers ${ }^{\dagger}$

0.127

1.65

Share of supplies from the largest supplier

0.007

Firm characteristics

Age of firm

0.417

$3.82 * * *$

Employment size

$-0.140$

$-2.21 * *$

State-owned

0.316

1.42

Foreign-owned or joint venture

$-0.175$

$-0.75$

Gross margin

1.236

$2.74 * * *$

Industry controls

Included

Included

City controls

Included

Included

Constant

3.609

5.30***

Adjusted $\mathrm{R}^{2}$

0.1425

${ }^{\dagger}$ The value is standardized by industry.

$* p<0.1$; ** $p<0.05$; *** $p<0.01$, one-tailed test.

The joint test (F-test) on location variables is significant at the 10-percent level. 
Table 5. Regression results, Hypotheses 2a-2c

Downstream supply chain attributes

Dependent variable:

Log DIF

Location proximity of customers

Within the same district (\%)

Within the same city (\%)

0.005

1.44

Within the same province (\%)

0.009

$2.51^{* *}$

Not same province in China (\%)

0.010

$3.17 * * *$

Overseas (\%)

$-0.002$

$-0.49$

Length of relationship with customers

$-0.133$

$-2.10 * *$

Relative power over customers

Number of customers ${ }^{\dagger}$

$-0.104$

$-1.23$

Share of sales to the largest customer

$-0.003$

$-1.17$

\section{Firm characteristics}

Age of firm

0.407

$3.88^{* * *}$

Employment size

$-0.189$

$-3.02 * * *$

State-owned

0.149

0.69

Foreign-owned or joint venture

$-0.487$

$-2.18^{* *}$

Gross margin

1.385

$3.11^{* * *}$

Industry controls

Included

Included

City controls

Included

Included

Constant

3.052

$4.89 * * *$

Adjusted $\mathrm{R}^{2}$

0.2545

${ }^{\dagger}$ The value is standardized by industry.

* $p<0.1$; ** $p<0.05$; *** $p<0.01$, one-tailed test.

The joint test (F-test) on location variables is significant at the 1-percent level. 
Table 6. Regression results, Hypothesis 3 (Dependent variable: Return on Sales)

\begin{tabular}{lcccccc}
\hline & All Industries & Apparel & Electronics & Automotive & Machinery & Food \\
\hline Log DIR & -0.025 & -0.054 & -0.054 & 0.007 & 0.014 & -0.006 \\
& $(-2.10)^{* *}$ & $(-2.58)^{* *}$ & $(-1.70)^{*}$ & $(0.46)$ & $(0.41)$ & $(-0.25)$ \\
Log DIF & -0.033 & 0.001 & -0.036 & -0.048 & -0.104 & -0.004 \\
& $(-2.86)^{* * *}$ & $(0.04)$ & $(-0.93)$ & $(-2.87)^{* * *}$ & $(-3.12)^{* * *}$ & $(-0.16)$ \\
Log DAP & 0.029 & 0.056 & 0.038 & 0.029 & 0.044 & -0.0002 \\
& $(2.81)^{* * *}$ & $(2.85)^{* * *}$ & $(1.35)$ & $(2.03)^{* * *}$ & $(1.42)$ & $(-0.01)$ \\
Log DAR & -0.002 & 0.009 & -0.016 & -0.014 & 0.026 & -0.004 \\
& $(-0.26)$ & $(0.59)$ & $(-0.76)$ & $(-1.21)$ & $(1.09)$ & $(-0.23)$ \\
Age of firm & -0.064 & -0.139 & -0.093 & 0.012 & -0.090 & 0.055 \\
& $(-2.82)^{* * *}$ & $(-3.69)^{* * *}$ & $(-1.40)$ & $(0.36)$ & $(-1.47)$ & $(1.21)$ \\
Employment size & -0.007 & -0.007 & 0.033 & -0.001 & -0.089 & 0.029 \\
& $(-0.51)$ & $(-0.25)$ & $(0.96)$ & $(-0.08)$ & $(-2.53)^{* *}$ & $(0.95)$ \\
State-owned & -0.005 & 0.237 & -0.096 & -0.091 & 0.109 & -0.035 \\
Foreign-owned/ & $(-0.11)$ & $(2.09)^{* *}$ & $(-0.84)$ & $(-1.37)$ & $(0.98)$ & $(-0.56)$ \\
Joint venture & -0.001 & 0.007 & -0.079 & -0.097 & -0.046 & 0.203 \\
Industry controls & $(-0.01)$ & $(0.08)$ & $(-0.61)$ & $(-1.57)$ & $(-0.27)$ & $(2.32)^{* *}$ \\
& Included & - & - & - & - & - \\
City controls & Included & Included & Included & Included & Included & Included \\
Constant & 0.653 & 0.591 & 0.867 & 0.124 & 0.952 & -0.092 \\
Adjusted R ${ }^{2}$ & $(5.43)^{* * *}$ & $(3.41)^{* * *}$ & $(2.39)^{* *}$ & $(0.90)$ & $(2.97)^{* * *}$ & $(-0.40)$ \\
& 0.1623 & 0.3015 & 0.1425 & 0.1396 & 0.1544 & 0.3453 \\
\hline
\end{tabular}

Coefficient estimates are in each cell, and $t$-values are in parentheses.

${ }^{*} p<0.1 ; * * p<0.05 ;{ }^{* * *} p<0.01$, one-tailed test. 